
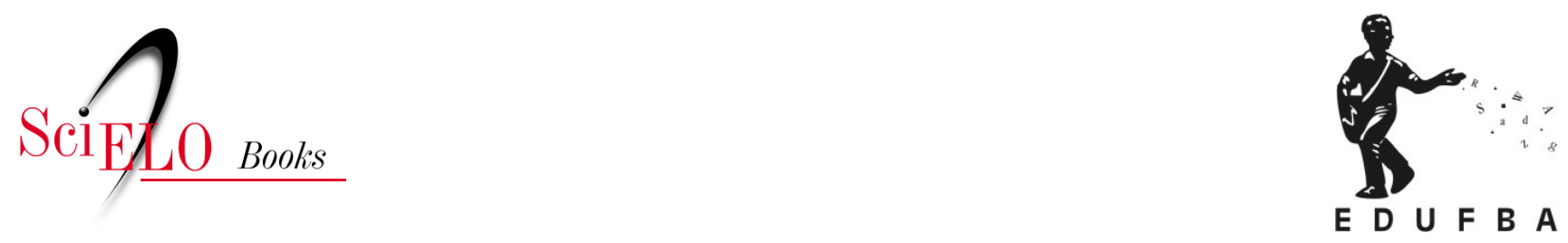

\title{
O que dizer da pobreza?
}

\author{
José Carlos da Exaltação Torres
}

\section{SciELO Books / SciELO Livros / SciELO Libros}

TORRES, J.C.E. O que dizer da pobreza? In: Cadastro Único: tecnologia de reclassificação social [online]. Salvador: EDUFBA, 2016, pp. 25-31. ISBN: 978-65-5630-011-5. https://doi.org/10.7476/9786556300115.0003.

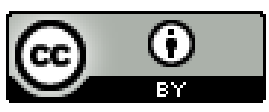

All the contents of this work, except where otherwise noted, is licensed under a Creative Commons Attribution 4.0 International license.

Todo o conteúdo deste trabalho, exceto quando houver ressalva, é publicado sob a licença Creative Commons Atribição 4.0. 


\section{O QUE DIZER DA POBREZA?}

O Senhor Fernando, Conde de Villar da Veiga, inquire e, em seguida, asperamente responde ao seu amigo Antonio Guerreiro, que encontrara ao Largo da Igreja das Chagas, em Lisboa, Portugal:

[...] O que é a pobreza [perguntou Fernando], não me dirás? Pensas que está na comparação absoluta dos meios de viver? Não. Está sobretudo nas necessidades relativas, nas differenças de posição, nas exigencias da sociedade. O que para uns é independencia, é para outros penuria; o que é dolorosa escassez para este que representa uma jerarchia, dá a abundancia áquelle, cuja condição, intelligencia e educação nem conhece, nem deseja mais. (LEAL JUNIOR, 1858, p. 50)

Essa impetuosa manifestação posta de súbito pelo Conde não deixa alternativa ao seu interlocutor, senão a concordância inconteste: "Assim é... dizes bem". (LEAL JUNIOR, 1858, p. 50)

Os versos proferidos pelo Conde de Villar da Veiga integram a produção teatral A pobreza envergonhada, ${ }^{6}$ obra literária lusitana, de autoria de Leal Junior, escrita em meados do século XIX (1858) e detentora de uma narrativa cativante, que põe a descoberto o drama vivido por famílias da alta sociedade portuguesa, desprovidas de suas posses e obrigadas pela posição nobiliárquica a encenar um status contrário à condição material em que efetivamente se encontram.

Nessa produção, Fernando é amigo de infância de Antonio Guerreiro, a quem havia anos não encontrava. No tempo em que estiveram afastados,

6 Todas as citações e expressões extraídas dessa obra obedecerão à grafia original. 
seu pai e única companhia, Conde de Villar da Veiga, falecera, deixando-lhe, além da solidão, o título e a falência financeira. Guerreiro, irmão de Amelia, filho de D. Luiza e do navegador Jeronymo Guerreiro, também perdera seu pai, falecido havia 15 anos, acometido de um ataque cardíaco, quando tentava impedir que um agente financeiro, João Rodrigues, aplicasse-lhe um golpe e roubasse o dinheiro que pretendia deixar de herança à sua família.

O Drama gira em torno da família Guerreiro e tem, na figura de João Rodrigues, o vilão, que se apropriara indevidamente da fortuna daquela família, antes mesmo de conhecê-la, quando Jeronymo Guerreiro lhe confiara por depósito suas economias, intentando resgatá-las posteriormente. O navegador descobriu a tempo o golpe, mas foi surpreendido por um ataque fulminante do coração, tamanha a apreensão em que se envolveu. O fato se deu na localidade da Figueira, em 30 de outubro de 1840, dia em que Rodrigues planejava fugir com o dinheiro de todos os seus credores, com o que pretendia construir o patrimônio de sua filha, ainda criança, aos três anos de idade, Hortensia, justificando-se pelo significado social que tinha a riqueza e na certeza da impunidade de seu ato. O encontro de Rodrigues com Jeronymo Guerreiro se deu ao acaso e muito brevemente, mas foi o suficiente para o negociante enredá-lo naquele golpe há muito planejado.

Oh! riqueza, riqueza!.. És a influencia, és o poder, és a consideração, és o respeito... és até a virtude! [...] É longo e cansa o caminho da probidade... não ha ver-lhe o fim. O mais breve é o melhor [...] A sociedade despresa estes meios? Talvez. Mas inclina-se diante dos resultados. (LEAL JUNIOR, 1858, p. 1-2)

À época, um funcionário de João Rodrigues, José Silvestre, percebe toda a movimentação e, surpreendendo o patrão, demonstra conhecer seus planos e insinua chantageá-lo, para beneficiar-se também dos resultados do golpe.

No comercio ha duas maneiras de enriquecer. Uma é demorada, custosa, semeada de vigilias e fadigas. Chama-se esta o trabalho.

$[\ldots]$

... é facil, rapida e commoda a outra maneira. Quer só larga consciencia e animo audaz. Aperta-se no rosto a mascara da hypocrisia; pela dissimulação attrahe-se a confiança; e um dia foge-se com os despojos dos 
credulos que se deixaram cair no laço de um credito matreiro. (LEAL JUNIOR, 1858, p. 6-7)

No desenrolar do prólogo, Silvestre fará, sozinho, uma reflexão sobre os meios e motivações para o enriquecimento de Rodrigues, mas sequer tentará impedi-lo, ao contrário, se ocupará em garantir suas próprias vantagens. É ele, ao fim, que ficará de posse do recibo comprovando o depósito de Jeronymo Guerreiro, aproveitando-se da confusão formada no momento da morte deste.

[...] Vinte familias sacrificou para calçar de oiro o pavimento em que estrebucha essa infancia turbulenta... mente á sociedade, mente á consciencia, mente a Deus, aos homens e a si... arruina, espolia, rouba... amontoa uma riqueza feita de miserias... prepara uma ventura composta de lagrimas... e tudo por aquella creança. (LEAL JUNIOR, 1858, p. 17)

Instalado em Lisboa após o exitoso golpe, cidade onde coincidentemente reside a família Guerreiro, João Rodrigues se torna uma eminente figura da alta sociedade. Proprietário de imóveis, é o locatário da residência dos Guerreiro, mas sequer desconfia ser a família daquele a quem havia uma década e meia empurrara para a morte. Essa família encontra-se exaurida de todos os seus recursos, mas D. Luiza oculta dos filhos (Antonio e Amelia) tal situação, até o momento em que João Rodrigues despeja a família por falta de pagamentos do aluguel.

Nas cenas do primeiro ato, aparecem novos personagens para o desenrolar do drama, dos quais se destacam Anna e Procopio, mãe e filho, ela empregada e devota da família Guerreiro, ele pintor, considerado à época um trabalhador braçal. Seraphina é vendedora de queijadas e é com quem Procopio pretende casar-se. Numa cena, encontram-se estes dois nas proximidades da Igreja das Chagas, ele a pintar e ela a vender suas queijadas. Em tom descontraído ela o inquire se não se envergonha de trabalhar aos domingos: "Não sabe que é prohibido?”. Ele retruca afirmando que "Nós cá os pobres não podemos esperdiçar estes ganchos". (LEAL JUNIOR, 1858, p. 27) Curiosamente, Seraphina parece não considerar também a sua atividade como um trabalho.

D. Amelia e D. Luiza frequentam a Igreja, da mesma forma que D. Hortensia, filha de João Rodrigues, a qual é membro de uma associação de caridade que recolhe doações para acudir aos necessitados. Pai e filha figuram, assim, dentre as famílias caritativas de Lisboa. Nesse contexto, reaparece 
também José Silvestre, agora como mendigo, ocupando as escadarias da Igreja das Chagas e sustentando uma dívida de gratidão para com D. Amelia Guerreiro, quem lhe dera a primeira esmola naquele lugar e que o repetia a todo domingo, tratando-o já com especial afeto: "O meu pobre dos domingos”. (LEAL JUNIOR, 1858, p. 40) Comparando-se essa expressão com a de Procopio, na cena anterior (LEAL JUNIOR, 1858, p. 27), pode-se observar que, no drama, assimila-se como pobre tanto o trabalhador braçal quanto aquele que mendiga. Corrobora isso a cena em que $\mathrm{D}$. Luiza virá a descobrir que Anna, sua empregada, ciente da situação financeira daquela família, está a dispor do seu próprio dinheiro para suprir as despesas da casa: "Obrigada, Anna. Não me envergonho de acceital-o [...] Acceitam-se os favores que vem de egual para egual [sic]”. (LEAL JUNIOR, 1858, p. 77, grifo nosso) Todos iguais até aí, na carência financeira, pois a postura de D. Luiza não será a mesma em relação àqueles a cujo status social sua família se equipara.

É também no cenário das Chagas que José Silvestre e João Rodrigues se reencontrarão. Passadas algumas cenas, Silvestre descobrirá que D. Luiza, D. Amelia e Antonio são os herdeiros de Jeronymo Guerrreiro e voltará a chantagear Rodrigues, ameaçando entregar o recibo que possuía aos verdadeiros donos, a menos que recebesse parte do dinheiro outrora roubado. João Rodrigues, usando de sua influência, fará com que José Silvestre seja recolhido "à casa de correção no asylo", acusando-o de ser "um mendigo vadio”. (LEAL JUNIOR, 1858, p. 153) Algum tempo depois, porém, encontram-se novamente e, com ironia, Silvestre lhe justifica o motivo da repentina liberdade: "Imagine o senhor que o tal asylo tem a vaidade de querer ser um refugio de indigentes e não uma casa de detenção”. (LEAL JUNIOR, 1858, p. 159) José Silvestre agora trabalha como negociante de fósforos e tem endereço fixo. É num episódio em sua casa que se reúne com Rodrigues para entregar o recibo em troca do dinheiro, mas João Rodrigues está armado e tenta obrigar-lhe à entrega sem troca. Como esperasse essa reação, José Silvestre saca de duas armas, rende Rodrigues e o obriga a partir, marcando um horário do dia seguinte, em lugar público, para a troca pretendida.

A relação de Rodrigues com sua filha Hortensia é quase de submissão. Desde a infância, cumpre-lhe todos os caprichos, mas isso não é suficiente para conquistar o seu afeto. D. Hortensia busca um casamento nobiliárquico, mas acumula reincidentes rejeições, as quais atribui à reputação de seu pai, em razão da forma como este enriqueceu: 
ha ainda consciencias escrupulosas para as quaes não basta nem a fortuna dos paes, nem a reputação dos filhos. [...] Continue então, meu pae. Engrosse cabedaes, amontoe thesouros... e eu que fique para ahi solitaria... ao despreso de todos. (LEAL JUNIOR, 1858, p. 109)

Ela seguirá obstinada o seu objetivo de casar-se com um nobre, pois não contenta-lhe a riqueza, é preciso o reconhecimento, o prestígio da posição ocupada: “Quero casar com um titular para emmudecer a inveja”. (LEAL JUNIOR, 1858, p. 118) Essa obstinação não tardará a tornar mais dolorosa a sorte dos Guerreiro, precisamente a de D. Amelia.

Fernando, o Conde, tem intenção de cortejar D. Amelia, mas, estando financeiramente arruinado, detém-se de fazê-lo. Não encontra quem lhe sirva de credor para honrar as dívidas deixadas pelo pai e vê-se já inclinado ao suicídio. Recorre derradeiramente a João Rodrigues, que nega-lhe de pronto a ajuda, mas, impelido pela filha, que vê aí a oportunidade de casar-se com um homem de título, concede um empréstimo. A primeira reação do Conde é pedir D. Amelia em casamento. Ela também é apaixonada por Fernando, mas vê-se obrigada a negar-lhe o pedido, pressionada por D. Hortensia, que ameaça suspender a ajuda do pai e condenar o Conde ao suicídio: "Não se queixe depois. Deixo á sua consciencia a responsabilidade dos resultados". (LEAL JUNIOR, 1858, p. 145) A trama se arranja de tal modo que Fernando e D. Hortensia ficam noivos, e da família Guerreiro não se tem mais sequer notícia. Em outra cena, se verá que essa família mudou-se para um bairro pobre, numa residência de extrema miséria, onde não há qualquer móvel ou mesmo alimento.

Procurando pelos Guerreiro, Procopio encontra José Silvestre e contalhe o infortúnio em que caíram. Mais tarde, ao acaso, encontra Antonio, o qual confessa-lhe a situação em que efetivamente se encontram, mas recusa ajuda de Procopio, afirmando que “a indigencia não deve servir de encargo á pobreza”. (LEAL JUNIOR, 1858, p. 176) Mas Antonio Guerreiro, que agora vê a realidade de um ângulo oposto ao que se acostumara a ver, quando inquirido por Procopio de "como tem vivido", responde num desabafo que se assemelha ao que fizera-lhe o seu amigo Fernando noutrora:

Deus sabe como!.. Nunca imaginei que no meio de uma cidade populosa... no seio de tanto fausto, de tanto luxo, de tamanho despendio, se podesse chegar a tal penuria... Não pensava então... não sabia... não sabia que Deus poz ao pé de cada pompa uma miseria, um infortunio ao pé de cada esplendor para lição da fraqueza humana e desengano das vaidades 
do mundo. Andei cego muitos annos... tenho aprendido em poucos dias. (LEAL JUNIOR, 1858, p. 175)

Ao fim, Antonio Guerreiro despede-se de Procopio e evita que este descubra onde sua família está abrigada. No mesmo cenário, à noite, Antonio e D. Amelia encontram-se casualmente, quando esta se dirige a ele, sem reconhecê-lo, para pedir esmola. Comovido, o irmão a pede que volte para casa e decide ele mesmo mendigar o pão de que precisam. Em casa, mãe e filha, não mais suportando o peso da miséria em que se encontram, decidem suicidar-se. Vedam a casa e acendem fogo, intentando sufocar-se. Por sua vez, Antonio, que está a mendigar, bate à porta de uma casa e desmaia em seguida. Essa é justamente a casa de José Silvestre, e o fato se deu momentos após a sua conversa com João Rodrigues. Quem o socorre é Silvestre e Procopio, que voltara a procurá-lo. O acontecido é o suficiente para que José Silvestre desistisse de sua empreitada com João Rodrigues.

Procopio leva Antonio para a casa de Anna e, após o reanimarem e o alimentarem, seguem em conjunto para a casa de D. Luiza, onde a encontram junto a sua filha, ambas já quase desfalecidas, mas ainda a tempo de salvá-las. Chegará mais tarde o prior, o pároco daquela localidade, convocado por Anna, para que possa constatar a situação e buscar ajuda para aquela família. Coincidentemente, a família caridosa a quem o prior recorrera foi a dos Rodrigues. Sem terem ideia de quem se tratava, João Rodrigues, D. Hortensia e seu noivo, o Conde de Villar da Veiga, chegam à residência. Reunidos todos, Antonio, recordando o que lhe dissera Silvestre quando o socorreu, de que sua herança estaria com o Rodrigues, o acusa, mas ainda sem provas. Também revela a trama de D. Hortensia para casar-se com Fernando, que imediatamente afasta-se da noiva e junta-se aos Guerreiro. João Rodrigues se diz ofendido, ameaça processar Guerreiro e intenta retirar-se. Aliás, estava ali mesmo incomodado, pois que passava já da hora que combinara o encontro com José Silvestre. Mas é o próprio Silvestre que chega também ao local, anunciando que já entregara aos tribunais o recibo provando a má fé de João Rodrigues. Em sua companhia chega o mesmo oficial de justiça que outrora o detivera, agora com ordens para prender João Rodrigues, quando se finaliza o drama.

Essa produção literária data de cerca de um século e meio atrás e tem como contexto a cidade de Lisboa, que dista um oceano das terras brasileiras. Carrega em si, portanto, o peso do tempo, o cansaço da viagem e os 
arredondados contornos que a arte literária lhe permite ter. Mas apresenta-se ainda com aparência juvenil e ostenta o vigor e a disposição de quem inicia uma jornada, alcançando os sentidos com implacável dureza e uma força cortante. Isto porque A pobreza envergonhada expõe os significados atribuídos à pobreza na sociedade moderna, o trauma de ser colocado na condição de dependência da caridade alheia e a inscrição simultânea no grupo dos que são socialmente desvalorizados, dos que não têm prestígio, daqueles a quem a sociedade não reconhece a existência ou reconhece atribuindo um estatuto inferior, pode-se dizer, uma localização indigna no “espaço social”, tomando por referência as formulações de Pierre Bourdieu (1996), como se verá a seguir. 